\title{
Construcții comparative în limba română veche
}

\author{
Raluca Brăescu* \\ Institutul de Lingvistică „Iorgu Iordan - Al. Rosetti”, Calea 13 Septembrie 13, 050711 București, România \\ Facultatea de Litere, Universitatea din București, Str. Edgar Quinet 5-7, 010017 București, România
}

\author{
Despre articol \\ Istoric: \\ Primit 23 mai 2017 \\ Acceptat 6 iunie 2017 \\ Publicat 30 septembrie 2017 \\ Cuvinte-cheie: \\ adjectiv \\ operator de grad \\ complement comparativ \\ topică \\ deplasare roll-up
}

\begin{abstract}
Rezumat
În articolul de față realizăm o analiză a construcțiilor cu adjective gradate în textele vechi românești. Ne oprim asupra comparativului de superioritate, astfel că avem în vedere, în primul rînd, stadiul de gramaticalizare a operatorilor de grad implicați. Structurile înregistrate în textele vechi includ unități polifuncționale în competiție, dintre care unele intră în procese complexe de specializare (mai), iar altele dispar (camai). În al doilea rînd, prezentăm realizările complementului comparativ în corpusul analizat: grupuri prepoziționale avînd drept centru prepozițiile de, decît și ca. Ne interesează în ce măsură se pot stabili restricții de utilizare a acestor prepoziții. Vom acorda o atenție specială „anomaliilor” de topică a unităților. Configurațiile în care complementul comparativ este antepus adjectivului se pun în legătură cu existența unor urme ale sintaxei nonconfiguraționale în limba română veche.
\end{abstract}

\section{Introducere}

Sistemul comparativ este reprezentat, în mod prototipic, printr-un ansamblu de expresii ce conțin un operator de grad și denotă o relaţie între un reper (o valoare standard sau o clasă de comparație) și o valoare a unui referent (gradul în care o entitate posedă o anumită proprietate). Sînt general acceptate mai multe configurații, corespunzătoare bine-cunoscutelor trepte: comparativ de superioritate (mai ... decit / ca), comparativ de inferioritate (mai puţin ... decît / ca), comparativ de egalitate (la fel de / tot atît de / tot aşa de ... ca), superlativ relativ (cel mai ... din / dintre). În mod tradițional, aceste valori sînt grupate, aşadar, într-o singură clasă, deși ele exprimă ipostaze diferite ale intensităţii unei însuşiri (o (in)egalitate, un paralelism, o analogie, o identitate, o variație proporţională sau de măsură).

Dintre analizele propuse asupra construcțiilor comparative o reținem pe aceea a lui Kennedy (1999) despre adjectivele gradabile, definite ca expresii ale unor puncte pe o scală semantică (expresii relaționale), în sensul că leagă obiecte de gradele unei scale specificate. O scală este o reprezentare abstractă a unui act de măsură, deci un parametru dimensional (un tip de proprietate) în care ordinea este reglementată prin grade. Adoptînd o analiză sintactică, Kennedy $(1999$, p. 83) arată că adjectivele gradabile proiectează o structură funcțională extinsă care are drept cap un morfem de grad.

În articolul de față propunem o analiză a construcțiilor comparative de superioritate ce includ adjective în textele vechi (originale și traduse), din secolele al XVI-lea - al XVIII-lea ${ }^{1}$. În studiile diacronice asupra gradării, se constată (Frâncu, 2009; Stan, 2013; Brăescu, 2015) că există numeroase unități care se delexicalizează, se gramaticalizează sau intră în procese de reanaliză pentru a deveni mijloace (prototipice sau emfatice) de expresie a gradelor de comparație. În cele ce urmează, vom avea în vedere: statutul operatorului de grad, realizările complementului comparativ și analiza unor aspecte de topică a unităților implicate $^{2}$.

\footnotetext{
*Adresă de corespondență: ralucabraescu@yahoo.com.

${ }^{1}$ Exemplele au fost extrase din corpusul de texte utilizat în cadrul proiectului The Syntax of Old Romanian (Pană Dindelegan, 2016).

${ }^{2}$ Punctul de plecare al prezentului articol este studiul Gradarea în limba română. Perspectivă istorică și tipologică, Proiectul 


\section{Structurile comparative de superioritate}

Într-o construcție completă, gradul comparativ de superioritate pune în relație doi termeni: adjectivul gradat (cu morfemul comparativ) și complementul comparativ. Operatorii înregistrați în textele vechi pentru marcarea gradului sînt: mai (< lat. MAGIS) ${ }^{3}$, principalul marcator în comparativele analitice latinești (1a-f), și camai $(1 \mathrm{~g}-\mathrm{j})$ :

(1) a. Că mai bunră e domniia ta decî<t $>$ viiața mea ( $\mathrm{PH}$.1500-1510, 51 $\left.1^{\mathrm{v}}\right)$

b. Mai iubite-s decî<t > aurulu și piatra cea curată multă şi mai dulce e de miiarea şi fagurul (PH.1500-1510, 15 ${ }^{\mathrm{r}}$ )

c. atunce cînd zua era mai caldă (PO.1582, 56)

d. lumina mai mică să slujască nopției (Po.1582, 13)

e. mai multe și mai greale sînt păcatele noastre $\left(\mathrm{CC}^{2} .1581,42\right)$

f. Și vor hi ceia ce vor rămînea mai scumpi decît aurul cel curat și omul va fi mai scump decît piatra zamfirul (DPar.1683, 31 ${ }^{\mathrm{v}}$ )

g. camai sărăcești și mai mici să sînt darurele noastre $\left(\mathrm{CC}^{2} .1581,124\right)$

h. cu atîta camai bun fiind decît îngerii cît camai osăbit decît dînşii au ocinat nume (DPar. $1683, \mathrm{IV} / 30^{\mathrm{v}}$ )

i. Să-m faci acoperemîntul camai frumos (Dvs.1682-6, 49 )

j. Și făcea camai vîrtoase și mai trudite rugile cu dînşii (DVs.1682-6, 209 )

Coocurența unor forme cu același rol, în structuri identice și fără reguli stricte de combinare reprezintă o trăsătură identificată în comportamentul tuturor operatorilor de grad din cadrul treptelor de gradare și este, de fapt, o trăsătură normală a oricărui sistem în formare. Unitatea mai devine din formă lexicală (din adverb) o formă gramaticală (marcă a comparativului), fără ca această schimbare să afecteze și unitatea camai (care nu va mai supraviețui).

Faptul că termenul mai nu era deplin gramaticalizat pentru marcarea comparativului de superioritate al adjectivului în epoca veche este demonstrat nu atît de poziţia sa prenominală (2a), cît de disponibilitatea spre dislocări $(2 \mathrm{~b}-\mathrm{d})$. De altfel, întreg grupul adjectival este plasat prenominal, tipar care își reduce mult frecvența pînă în limba actuală. Statutul de marcator negramaticalizat al lui mai (sau camai) este susţinut nu numai prin argumente legate de topica unităților, ci și de asocierea cu adverbe (3a,b) sau cu adjective intensificate $(3 \mathrm{c})$.

(2) a. Că mai mare sfînt de Ioan Botezătorul n-au fost nimea $\left(\mathrm{CC}^{1} \cdot 1567,17^{\mathrm{r}}\right)$

b. Aceia sînt orbi în suflet: mai în mare perire sînt $\left(\mathrm{CC}^{1} .1567,76^{\mathrm{v}}\right)$

c. Acest păgîn mai om bun au fost decît acești creștini $\left(\mathrm{CC}^{1} .1567,64^{\mathrm{r}}\right)$

d. după aceaia şi împărăţiia ceriului dă noao, ca un iubitoriu şi mai cu multă cinste despuitoriu $\left(\mathrm{CC}^{2} .1581,545\right)$

(3) a. Și să făcură glasurile trîmbiții mergînd înainte mai tare foarte (Bв.1688, XIX)

b. glasurile trîmbitei întrecînd camai tare foarte (DPar.1683, III/38 $8^{\mathrm{v}}$ )

c. Destui mai credincioși sînt $\left(\mathrm{CC}^{2} .1581,381\right)$

Cultura română și modele culturale europene: cercetare, sincronizare, durabilitate, cofinanțat de Uniunea Europeană și Guvernul României din Fondul Social European prin Programul Operaţional Sectorial Dezvoltarea Resurselor Umane 2007-2013, contractul de finanțare nr. POSDRU/159/1.5/S/136077.

${ }^{3}$ Și alte limbi romanice folosesc pentru comparativ continuatorul lui MAGIS: sp. más, port. mais, cat. mes, în timp ce franceza și italiana au preferat continuatorul lui plus (fr. plus, it. piü). Se cunosc varietăți lingvistice (cum este provensala) în care se întîlnesc atît forme cu mais, cît și forme cu plus (Lüder, 1996, p. 30). În versiunile vechi ale limbilor romanice, se manifestă, ca și în româna veche, un grad ridicat de variație. Astfel, în spaniola veche (din secolul al X-lea) au fost înregistrate (Lapesa, 1981, p. 91) structuri cu plus: plus áspero. Aspecte similare, legate de utilizarea lui plus au fost relevate și în catalana veche (pus). 
Acest comportament instabil al unităților din structurile comparative din perioada veche i-a condus pe unii cercetători (Ciompec, 1985, p. 156) să realizeze o periodizare: în primele texte, construcția comparativă „avea caracter de formație premorfologică” și abia după secolul al XVII-lea sînt atestate construcțiile cristalizate, fixate, înregistrate în forma actuală a limbii române.

În combinație directă cu verbul, atît mai, cît și camai funcționează ca adverbe modale („mai mult”), exprimînd singure ideea de comparativ (Ciompec, 1985, p. 155), utilizări absente din limba actuală (4af). Structurile ilustrează un alt fenomen interesant din punct de vedere tipologic. În limba română, se cunosc două fenomene paralele: pe de o parte, se poate observa în texte traseul de specializare al operatorului de gradare mai; pe de altă parte, se constată scăderea frecvenței (pînă la dispariția din limba actuală) a adverbului modal mai în favoarea cuantificatorului mai mult (în domeniul verbal). În alte limbi romanice (franceză, italiană, spaniolă), aceeași unitate (fr. plus, it. più, sp. más) funcționează deopotrivă în context verbal și nominal, cumulînd (sau actualizînd în paralel) funcțiile de cuantificator și de operator de grad (Zafiu, 2006, p. 217). Contextele înregistrate (4a-f) în textele vechi demonstrează că diferența de funcționare și de statut a operatorului în română și în limbile romanice nu era deloc tranşantă (aşa cum se întîmplă în limba actuală, vezi Zafiu, 2006, p. 218).

(4) a. Mai decît om bătrîru înțeleș, că porîncitele tale cerșuiu (PH.1500-1510, 106 ${ }^{\mathrm{v}}$ )

b. mai decît neaoa înrălbi-me-voiu (PH.1500-1510, 43 )

c. ei mai iubesc pre Dumnezeu decît pre avuția lor $\left(\mathrm{CC}^{1} .1567,155^{\mathrm{r}}\right)$

d. derept aceaia, mai gîndesc de bogăţia ceștii lumi decît de bogăţia lu Dumnezeu (cc ${ }^{1} .1567$, $\left.145^{\mathrm{v}}\right)$

e. ocară ca aceasta mai iubişi-o decît cea slavă prea împodobită (svi 1670, $4^{\mathrm{v}}$ )

f. Nu e nice un rău mai de veninul șarpelui (FD.1592-604, 471 ${ }^{\mathrm{v}}$ )

Mai și camai apar utilizate ca semiadverbe sau clitice adverbiale cu rol aditiv temporal („din nou, încă o dată, deja”) încă din cele mai vechi texte $(5,6)$. În timp ce primul rămîne foarte productiv și în limba actuală, cel de-al doilea dispare:

(5) a. pohta lui nu și-o mai poate domoli $\left(\mathrm{CC}^{2} .1581,505\right)$

b. E cînd amu aceastea toate fi-vor, cine va mai putea sta? $\left(\mathrm{CC}^{2} .1581,692\right)$

(6) a. De-acmu n-oi camai purta păcatele voastre! (DPar.1683, II/2 ${ }^{\mathrm{r}}$ )

b. numele lui să nu să camai pomenească! (DPar.1683, III $/ 37^{v}$ )

În context nonverbal, mai funcționează ca adverb slab nonclitic, cu un grad de deficiență ${ }^{4}$ mai mare decît al altor adverbe slabe. În context adverbal, mai funcționează ca adverb clitic. Delimitarea adverbelor clitice de cele slabe nonclitice s-a făcut pe baza unor trăsături sintactice, dintre care topica a fost cea mai importantă.

\section{Realizările prepoziționale ale complementului comparativ}

Complementul comparativ este termenul cu rol de standard, de reper din cadrul unei construcții comparative. Prin caracterul său obligatoriu, impus de o configuraţie sintactică binară, el este interpretat în studiile recente (GALR, II; GBLR) ca un complement al mărcii de gradare (şi nu ca un circumstanţial de mod, așa cum apărea în lucrările tradiționale). În general, complementul comparativ are o structură eliptică, provenind dintr-o propoziție redusă la unul sau mai multe dintre componentele sale (GALR, II, p. 473-485). De altfel, numeroase studii de interes tipologic se opresc asupra complexităţii structurilor

\footnotetext{
${ }^{4}$ Distincția la nivelul deficienței (fonologice, morfologice, semantice sau sintactice) între clitice și adverbele slabe a fost pusă în evidență și de Reinheimer Rîpeanu (2004), cu referire la mai, cam, prea, tot, și. Pentru analiza diferitelor unități mai în limba veche vezi și Donazzan \& Mardale (2010); Mîrzea Vasile (2012, p. 129-151); Brăescu (2017, p. 79-96).
} 
comparative (care au la bază fenomene de elipsă și de reorganizare) și asupra multiplelor interpretări pe care le ridică (Pană Dindelegan, 2003; Zafiu, 2006).

Complementul comparativ este selectat de operatorul de grad (Cornilescu, 2008) şi se realizează, în mod prototipic, ca GPrep, avînd drept centru prepozițiile $c a$, decît, de. Aceste restricții se manifestă la distanţă, în sensul că adjectivul sau alte unităţi intervin între operatorul comparativ și complementul comparativ.

Construcțiile cu complemente comparative de inegalitate au înregistrat un grad ridicat de variație și în latină, în ceea ce privește marcarea complementului comparativ (ILR, p. 266; Stoica, 2015). Acesta se exprima analitic, prin construcția cu quam (7a) sau sintetic, prin ablativ (7b). Structurile nu erau interpretate ca simple variante, ci funcționau mai degrabă în distribuție complementară: construcțiile cu ablativ apăreau în expresii proverbiale, în structuri negative sau în întrebări retorice (Ledgeway, 2012, p. 23). Varianta sintetică a complementului comparativ va fi înlocuită în latina vulgară prin construcții analitice noi cu prepoziția $a b$, dar mai ales cu prepoziția $d e+$ acuzativ / ablativ (7c):

(7) a. clarior quam sol

b. sole clarior

c. melior de aliquo

Tiparul analitic preluat de limbile romanice se caracterizează la rîndul său prin variația realizărilor GPrep. Astfel, construcția cu quam (>ca) se va menține în portugheza veche, în dialectele din italiana veche sau în română (Salvi, 2011, p. 338) și va fi înlocuită de structura cu que / che, de / di sau de forme analitice noi: rom. decît, it. di quanto, sp. de lo que, port. do que.

În primele texte vechi din limba română, am înregistrat complemente comparative realizate ca grupuri prepoziţionale organizate în jurul constituenților decît (8) și de (9). Mărcile comparaţiei de inegalitate apar frecvent în variație liberă (10) și nu se pot stabili constrîngerile sintactice de utilizare ${ }^{5}$ (Ciompec, 1985, p. 156; Ciobanu, 2007; Stan, 2013).

(8) a. Că mai mare vătămătură decît trufa și măriia nu iaste, nice mai iute decît măriia și trufa $\left(\mathrm{CC}^{2} .1581,3\right)$

b. dărui lui ce era decît toate mai frumos $\left(\mathrm{CC}^{1} .1567,9^{\mathrm{r}}\right)$

c. să ținem pre toți mai buni decît noi $\left(\mathrm{CC}^{1} .1567,63^{\mathrm{v}}\right)$

d. nu avem noi alt nimic mai strălucitor și mai luminat decît soarele sau mai alb decît zăpada $\left(\mathrm{AD} .1722-5,9^{\mathrm{r}}\right)$

e. se va lumina Fiiul tău în ceriu vîrtosu, mai luminosu de șapte ori decît soarele ( $\mathrm{CS}_{\mathrm{IV}}$. 1590 $602,18^{\mathrm{v}}$ )

f. cu mai multă trudă înjugată iaste, decît cu veselie $\left(\mathrm{CC}^{2} .1581,27\right)$

(9) a. Aduceți-vă aminte de cuvînt ce eu am zis voao: că nu iaste robul mai mare de domnu-său $\left(\mathrm{CC}^{2} .1581,256\right)$

b. oaminii ficiorilor lu Izdrail mai mulți-s și mai tari de noi (PO.1582, 180)

c. du-te de la mine, că de mine cu mult mai putearnic te-ai făcut (Po.1582, 86)

d. că mai frumoasă fată de aceasta n-am vădzut $\left(\mathrm{Cs}_{\mathrm{Xx}} \cdot 1583-619,91^{\mathrm{v}}\right)$

e. nu vă teamereți amu, de multe pasări mai buni seți voi $\left(\mathrm{CC}^{1} .1567,129^{\mathrm{v}}\right)$

f. Dup-aceea le va da cununi în capul loru, mai luminate de soarele $\left(\mathrm{CS}_{\mathrm{v}} \cdot 1590-602,47^{\mathrm{v}}\right)$

(10) a. în ceastă lume să nu aibi nemică de să-ți fie mai drag și mai scump decît Dumnezeu, de să nu iubești mai vîrtos de Dumnezeu nece tată-tău, nece mumă-ta $\left(\right.$ CC $\left.^{1} .1567,132^{v}\right)$

\footnotetext{
${ }^{5}$ S-a constatat (Ciobanu, 2007, p. 170) că textele vechi din secolul al XVI-lea (cV.1563-8, CT.1560-1, Po.1582) ca și unele texte mai tîrzii (NT.1648, A.1620) preferă construcția cu de. Alte texte (precum CC $^{2} .1581$ ) folosesc cu precădere construcția cu decît. În scrisori și în documente, construcția cu de apare destul de rar, pe cînd cea cu decît nu apare niciodată.
} 
b. mai închinată și mai fericită ca o împărăteasă a lumii, de toți credincioșii pămîntului și sub bezne mai strașnică și mai înfricoșată asupra dracilor decît toți sfinții (AD.1722-5, $\left.16^{\mathrm{r}}\right)$

În numeroase contexte comparative (inclusiv cu adverbe), cele două părți ale unității decît apar nefuzionate - prepoziția de și adverbul cît (11). Sudarea celor două componente reflectă numai o convenție de scriere înregistrată în unele texte vechi:

(11) a. feace ciudă mai mare și mai minunată de cît toate ciudesele $\left(\mathrm{CC}^{2} .1581,109\right)$

b. Că era și mai prost mai vîrtos de cît alalți $\left(\mathrm{CC}^{2} .1581,297\right)$

c. spăla-mă-vei și mai vîrtos de cît zăpada mă voi albi (DDL.1679, 208)

Funcția de prepoziție a termenului decît este interpretată (Cornilescu, 2008) ca un tip de variație sau ca o formă cu un caracter oscilant în termenii teoriei reanalizei (prin schimbarea funcției gramaticale). Autoarea înțelege reanaliza în accepția lui Haspelmath (1998), ca interpretarea diferită a aceluiași șir, din punctul de vedere al constituenței sau al categoriilor sintactice atribuite constituenților, proces care are loc prin trecerea de la o generație la alta.

Construcția comparativă cu de continuă tiparul latinesc popular (Densusianu, 1938, p. 380-381; Rosetti, 1986, p. 512; Ciompec, 1985, p. 156). O particularitate sintactică a prepoziției de, în structurile comparative, este aceea că se construiește cu un nume articulat definit (12a,b), în absența altor constituenți dependenți de nume (Stan, 2013). Ca o contrapondere, prepoziţia decît apare construită cu un nume nearticulat $(12 c, d)$ :

(12) a. [Hristos] aceastea toate făcea-le mai vîrtos de omul $\left(\mathrm{CC}^{2} .1581,272\right)$

b. Iară Domnul arătă că și de vulpile și de pasările mai sărac iaste $\left(\mathrm{CC}^{2} .1581,277\right)$

c. trupul mai slab iaste decît suflet $\left(\mathrm{CC}^{2} .1581,424\right)$

d. Mai bunu-i ospățul cu verdeață de prieteșug și de har decît vițel de iasle cu vrajbă (DPar. $\left.1683, \mathrm{III} / 7^{\mathrm{v}}\right)$

În sistemul comparației actuale, $d e$ și-a restrîns utilizările și s-a specializat pentru exprimarea construcției de măsură (Niculescu, 1999, p. 186), în timp ce decit și-a extins uzul și s-a impus în structura complementului comparativ (Stan, 2013, p. 310; GR, p. 506).

În texte mai tîrzii, din secolul al XVII-lea, este atestat și ca (Frâncu, 2009, p. 198; Ciobanu, 2007), cu ocurențe sporadice în secolul al XVI-lea (13a,b), ceea ce sugerează faptul că era într-o fază incipientă de gramaticalizare (vezi și Niculescu, 1999, p. 187-188; Stan, 2013, p. 311). Structura cu prepoziția ca a fost respinsă la început și considerată un „provincialism muntenesc cu totul greșit” (Tiktin, 1945, p. 68). Preferința pentru construcția cu decît (în defavoarea celei cu prepoziția $c a$ ) este susținută și de lucrările ulterioare: „foarte des, decît este înlocuit prin $c a$ în limba vorbită și chiar și în limba literară. Vorbitorii atenți și scriitorii buni evită această construcție” (Iordan et al., 1967, p. 115).

(13) a. la noi nice un lucru nu-i mai bun și mai cu folos ca ceaea cind murim pentru credința cea bună (DVs.1682-6, 15v)

b. Și nu iaste alta mai de folos și mai înfrîmsețată, ca dragostea ceaia nefățarnica ( $\mathrm{CC}^{2} .1581$, 140)

Structurile comparative de inegalitate includ și un tipar incomplet, în care lipsește complementul comparativ (14a). În aceste contexte, complementul comparativ se subînțelege din context, deci poate fi recuperat. Am înregistrat și un al doilea tipar eliptic în limba veche, din care lipsește marcatorul mai, dar apare complementul comparativ. Acest tipar, care nu a supraviețuit în limba actuală, demonstrează că relaţia de coocurență a complementului comparativ cu operatorul de grad nu era obligatorie în perioada veche (Ciompec, 1985, p. 162) (14b,c): 
(14) a. atunce el în mai mare grije iaste $\left(\mathrm{CC}^{2} .1581,79\right)$

b. Bunru e mie leagea rrostului tău decît o mie de aur și de argint (PH.1500-1510, 105 ${ }^{\mathrm{r}}$ )

c. ca o sfîntă ce iaste decît toții sfinții $\left(\mathrm{AD} .1722-5,120^{\mathrm{r}}\right)$

Numeroase structuri înregistrate în textele vechi (15) realizează un fel de comparație generalizată (Ciompec, 1985, p. 164), se apropie de construcțiile superlative și includ un complement prepozițional cu prepoziția dentre / dentru (15a), preste (15b), pre (15c):

(15) a. Că adică și dentru îngeri, carele era mai mare, trufa-l lepădă den ceriu $\left(\mathrm{CC}^{2} .1581,3\right)$

b. fu mai mare preste toți în casa ei (DVs.1682-6, 62 $2^{\mathrm{v}}$ )

c. mai mare e și mai înraltu e pre toți oamenrii ( $\left.\mathrm{PH} .1500-1510,81^{\mathrm{v}}\right)$

\section{Topica unităților în construcțiile comparative}

Am înregistrat în textele vechi pe lîngă ordinea canonică din limba actuală [operator + adjectiv + complement comparativ (16a)] și numeroase structuri cu complement antepus (16b-e) (Brăescu et al., 2015). Construcțiile cu complement comparativ antepus adjectivului, identificate în continuare și în texte poetice sau populare din secolul al XIX-lea, mai sînt prezente în limba actuală (16f) numai în texte religioase cu limbaj arhaizant (Zafiu, 2006, p. 217):

(16) a. Că altă moarte nu era mai spurcată și mai fără de cinste decît răstignitura $\left(\mathrm{CC}^{2} \cdot 1581\right.$, 68)

b. decît un iepure mai slabă și mai pemintiană a fi $($ CII 1705, 32)

c. decît stîrvul împuţit tot mai dulce iaste (CII 1705, 38)

d. Decît credința și nădejdia iaste mai mare dragostea $\left(\mathrm{AD} .1722-5,22^{\mathrm{r}}\right)$

e. și dintr-atîta lumină ce avea s-au făcut decît toate negreșele și decît toate întunearicile mai negru și mai întunecat $\left(\mathrm{AD} .1722-5,44^{\mathrm{v}}\right)$

f. roagă-te pentru mine, netrebnicul și decît toți mai păcătosul (limbaj bisericesc)

Structurile cu complemente plasate în antepoziție în limba română veche sînt prezente și în alte limbi romanice vechi, de exemplu italiana veche (Giusti, 2010, p. 596-598; Poletto, 2014, p. 76). Aceste configurații au fost asociate (Ledgeway, 2012; Brăescu et al., 2015; Brăescu \& Dragomirescu, 2017) cu structurile discontinue și puse în legătură cu existența unor urme ale sintaxei nonconfiguraționale în româna veche, relicve ale trecerii de la latină. Dispariția construcțiilor de la (16b-e) se explică printr-o schimbare în setarea parametrului centrului de la structuri parțial head-final la structuri head-initial și prin fixarea unei sintaxe configuraționale (în care relațiile dintre constituenți sînt codificate prin topică).

Pentru a explica ordinea centrelor și a complementelor (variația dintre structurile dominante cu headinitial și structurile arhaice cu head-final), Ledgeway (2012) folosește conceptul de roll-up: aşa-zisa libertate de topică înregistrată în latină este explicabilă prin existența deplasărilor de tip roll-up, iar topica mai rigidă a limbilor romanice este determinată de pierderea acestui tip de deplasare.

În această perspectivă, schimbările petrecute în trecerea de la latină la limbile romanice nu mai par atît de tranșante (Brăescu et al., 2015): latina era o limbă în care se manifesta competiția între sintaxa head-initial (inovație) și sintaxa head-final (arhaism), așa cum erau și limbile romanice vechi (cel puțin româna și italiana); schimbarea completă de la sintaxa head-final la sintaxa head-initial se înregistrează în limbile moderne. După cum era de așteptat, limbile romanice vechi (inclusiv limba română veche) erau mai apropiate de latină în domeniul ordinii cuvintelor. 


\section{Concluzii}

Construcțiile comparative de superioritate, definite ca structuri complexe care exprimă o relaţie între o proprietate și un termen reper, cunosc în diacronie mai multe configurații sintactice. Am urmărit în articolul de față trei aspecte ale acestor construcții: traseul de gramaticalizare al operatorului mai, realizările prepoziționale ale complementului comparativ și analiza topicii unităților din construcțiile comparative, aşa cum reies din textele de limbă veche analizate.

Specializarea operatorului mai pentru exprimarea gradului comparativ de superioritate s-a realizat ca urmare a mai multe procese desfășurate pe parcursul secolelor al XVI-lea și al XVII-lea: dispariția unei unități aflate în competiție în limba veche (camai) și dispariția unității adverbiale mai cu sens lexical plin (modal). Coocurența unor forme cu același rol, în sintagme similare și fără constrîngeri evidente reprezintă o caracteristică a unui sistem gramatical în formare.

Complementul comparativ din structurile comparative de superioritate s-a realizat în limba română veche analitic, prin mai multe construcții prepoziționale. Am analizat distribuția construcțiilor cu prepozițiile de, decît și ca. Emergența expresiilor analitice înregistrate diacronic exemplifică (Ledgeway, 2012) o tendință a structurilor sintetice slăbite și predispuse de a fi înlocuite progresiv cu alte construcții în competiție și de fi subiectul unor procese de gramaticalizare.

În privința topicii complementului comparativ, am tratat îndeosebi tiparul „deviant” față de ordinea cuvintelor din limba actuală - tiparul cu complement comparativ antepus adjectivului. Am explicat structurile de acest tip prin modelul teoretic propus de Ledgeway (2012), potrivit căruia în trecerea de la latină la limbile romanice s-a făcut și trecerea de la construcții de tip head final la construcții de tip head initial și s-a fixat sintaxa configuraţională. În stadiile vechi ale limbii române, în care numeroase structuri erau în competițe, topica era mult mai liberă.

\section{Bibliografie}

\section{A. Corpus}

A.1620 = Alexandria, în Zgraon, Fl. (ed.), Cele mai vechi cărți populare în literatura română, vol. 11, Fundația Națională pentru Știință și Artă, București, 2006.

AD.1722-5 = Antim Ivireanul, Didahii, în Antim Ivireanul, Opere, ed. G. Ștrempel, Editura Minerva, București, 1972, p. 1238.

Bв.1688 = Biblia adecă Dumnezeiasca Scriptură a Vechiului și Noului Testament, tipărită întîia oară la 1688 în timpul lui Șerban Vodă Cantacuzino, Domnul Țării Românești, Editura Institutului Biblic, București, 1977.

$\mathrm{CC}^{1} .1567=$ Coresi, TîlculEvangheliilor, în Coresi, Tîlcul evangheliilor șimolitvenic românesc, ed. V. Drimba, Editura Academiei Române, București, 1998.

$\mathrm{CC}^{2} .1581$ = Coresi, Cartea cu învățătură, în Diaconul Coresi, Carte cu învățătură (1581), vol. I, Textul, ed. S. Pușcariu \& Al. Procopovici, Atelierele Grafice Socec, București, 1914.

CII 1705 = Dimitrie Cantemir, Istoria ieroglifică, în D. Cantemir, Opere complete, IV. Istoria ieroglifică, ed. S. Toma, Editura Academiei, București, 1974.

$\mathrm{CS}_{\mathrm{IV}, \mathrm{v}}$. 1590-602, $\mathrm{CS}_{\mathrm{XI}} .1583-619$ = Chivu, Gh. (ed.) (1993). Codex Sturdzanus, Editura Academiei Române, București. Cт.1560-1 = Coresi, Tetraevanghel, în Dimitrescu, Fl. (ed.) (1963). Tetraevanghelul tipărit de Coresi, Brașov, 1560-1561, comparat cu Evangheliarul lui Radu de la Mănicești, 1574, Editura Academiei, București.

Cv.1563-83 = Codicele Voronețean, ed. M. Costinescu, Editura Academiei Române, București, 1981.

DDL.1679 = Dosoftei, Dumnezăiasca liturghie, ed. N. A. Ursu, Mitropolia Moldovei și Sucevei, Iași, 1980.

DPar.1683 = Dosoftei, Parimiile preste an, 1683, ed. M. Ungureanu, Editura Universității „Alexandru Ioan Cuza”, Iași, 2012. Dvs.1682-6 = Dosoftei, Viața și petreacerea svinților, Iași.

FD.1592-604 = Floarea darurilor, în Roman Moraru, Al. (ed.) (1996). Cele mai vechi cărți populare în literatura română, 1,

Editura Minerva, București, p. 119-182.

NT.1648 = Noul Testament, Editura Reîntregirea, Alba Iulia, 1998.

PH.1500-1510 = Psaltirea Hurmuzaki, ed. I. Gheție \& M. Teodorescu, Editura Academiei Române, București, 2005.

Po.1582 = Palia de la Orăștie, ed. V. Pamfil, Editura Academiei RSR, București, 1968.

SVI 1670 = Varlaam și Ioasaf, în Stanciu Istrate, M. (2013). Reflexe ale medievalității europene în cultura română veche: Var-

laam și Ioasaf în cea mai veche versiune a traducerii lui Udrişte Năsturel, Editura Muzeului Național al Literaturii Române,

București. 


\section{B. Referințe}

Brăescu, R. (2015). Gradarea în limba română. Perspectivă istorică şi tipologică, Editura Muzeul Literaturii Române.

Brăescu, R., Dragomirescu, A. \& Nicolae, Al. (2015). (Non-)configurationality and the internal syntax of adjectives in old Romanian, în „Bucharest Working Papers in Linguistics”, vol 17, nr. 2, p. 55-74.

Brăescu, R. (2017). Mărci de comparație in textele vechi, în Dragomirescu, A., Nicolae, Al., Stan, C. \& Zafiu, R. (eds), Sintaxa ca mod de a fi. Omagiu Gabrielei Pană Dindelegan, la aniversare, Editura Universităţii din București, București, p. 79-86.

Brăescu, R. \& Dragomirescu, A. (2017). (Non) configuraționalitate in sintaxa adjectivului din româna veche, în „Actele celui de-al VI-lea Simpozion internațional de lingvistică", sub tipar.

Ciobanu, F. (2007). Complementul, în Avram, M. (ed.), Sintaxa limbii române în secolele al XVI-lea - al XVIII-lea, Editura Academiei Române, București, p. 117-188.

Ciompec, G. (1985). Morfosintaxa adverbului românesc, Editura Științifică și Enciclopedică, București.

Cornilescu, A. (2008). Reanalizăşi gramaticalizare: structura lui decît, în Pană Dindelegan. G. (ed.), Limba română - dinamica limbii, dinamica interpretării, Editura Universității din București, București, p. 203-212.

Densusianu, O. (1938). Histoire de la langue roumaine, vol. II, Ernest Leroux, Paris. Ed. rom.: Istoria limbii române, ed. J. Byck, Editura Științifică, București, 1961.

Donazzan, M. \& Mardale, Al. (2010). Additive and aspectual adverbs: towards an analysis of Romanian mai, în „Revue roumaine de linguistique", 3, p. 247-269.

Frâncu, C. (2009). Gramatica limbii române vechi (1521-1780), Casa Editorială Demiurg, Iași.

GALR = Guțu Romalo, V. (coord.) (2008). Gramatica limbii române, I. Cuvîntul, II. Enunțul, Editura Academiei, București; ed. I-a: 2005.

GBLR = Pană Dindelegan, G. (ed.) (2010). Gramatica de bază a limbii române, Editura Univers Enciclopedic, București.

Giusti, G. (2010). Il sintagma aggettivale, în Salvi, G. \& Renzi, L. (eds), Grammatica dellitaliano antico, Il Mulino, Bologna, p. 593-615.

GR = Pană Dindelegan, G. (ed.) (2013). The Grammar of Romanian, Oxford University Press, Oxford.

Haspelmath, M. (1998). Does grammaticalization need reanalysis?, în „Studies in Language”, 22, p. 315-351, Crossref.

ILR = Graur, Al. (ed.) (1965). Istoria limbii române, I, Editura Academiei, București.

Iordan, I., Guțu Romalo, V. \& Niculescu, Al. (1967). Structura morfologică a limbii române contemporane, Editura Științifică, București.

Kennedy, C. (1999). Projecting the adjective: the syntax and semantics of gradability and comparison, Garland Press, New York, Crossref.

Lapesa, R. (1981). Historia de la lengua española, Gredos, Madrid.

Ledgeway, A. (2012). From Latin to Romance. Morphosyntactic Typology and Change, Oxford University Press, Oxford, Crossref.

Lüder, E. (1996). Procedee de gradație lingvistică, Editura Universității „Alexandru Ioan Cuza”, Iași.

Mîrzea Vasile, C. (2012). Eterogenitatea adverbului românesc, Editura Academiei Române, București.

Niculescu, A. (1999). Individualitatea limbii române intre limbile romanice, vol. III, Editura Clusium, Cluj-Napoca.

Pană Dindelegan, G. (2003). Elemente de gramatică. Dificultăți, controverse, noi interpretări, Editura Humanitas, București.

Pană Dindelegan, G. (ed.) (2016). The Syntax of Old Romanian, Oxford University Press, Oxford, Crossref.

Poletto, C. (2014). Word Order in Old Italian, Oxford University Press, Oxford, Crossref.

Reinheimer Rîpeanu, S. (2004). Intensification et atténuation en roumain. Les adverbes cam, mai, prea, și, tot, în Araujo Carreira, M.H. (ed.), Intensification et atténuation dans les langues romanes, Université Paris 8 Vincennes - Saint Denis, p. $225-246$.

Rosetti, A. (1986). Istoria limbii române de la origini pînă la începutul secolului al XVII-lea, Editura Științifică și Enciclopedică, București; ed. I-a: 1938.

Salvi, G. (2011). Morphosyntactic Persistence, în Maiden, M., Smith, J.C. \& Ledgeway, A. (eds), The Cambridge History of the Romance Languages, I. Structures, Cambridge University Press, Cambridge / New York, p. 318-381, Crossref.

Stan, C. (2013). O sintaxă diacronică a limbii române vechi, Editura Universității din București, București.

Stoica, G. (2015). The Adjectival Category of Intensity. From Latin to Proto-Romanian, în Pană Dindelegan, G., Zafiu, R., Dragomirescu, A., Nicula, I., Nicolae, Al. \& Esher, L. (eds), Diachronic Variation in Romanian, Cambridge Scholars Publishing, Newcastle upon Tyne, p. 123-150.

Tiktin, H. (1945). Gramatica română, ediția a III-a revăzută de I.-A. Candrea, Editura Tempo, București; ed. I-a: 1893-1895.

Zafiu, R. (2006). Construcții comparative, în Pană Dindelegan, G. (ed), Limba română - Aspecte sincronice și diacronice, Editura Universităţii din București, București, p. 215-222. 